\title{
Practical guide to the management of acute pancreatitis
}

\author{
George Goodchild, ${ }^{1}$ Manil Chouhan, ${ }^{2}$ Gavin J Johnson ${ }^{1}$
}

\begin{abstract}
'Department of Gastroenterology, University College Hospital, London, UK ${ }^{2}$ Department of Radiology, University College Hospital, London, UK
\end{abstract}

\section{Correspondence to}

Dr Gavin J Johnson, Department of Gastroenterology, University College Hospital, London, NW1 2BU, UK; gavin.johnson2@ nhs.net

Received 22 October 2018 Revised 3 December 2018 Accepted 9 December 2018 Published Online First

2 March 2019

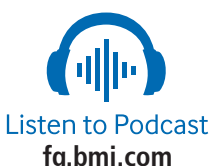

\section{Linked}

- http://dx.doi.org/10.1136/ flgastro-2019-101192

\section{Check for updates}

(C) Author(s) (or their employer(s)) 2019. No commercial re-use. See rights and permissions. Published by BMJ.

To cite: Goodchild G, Chouhan M, Johnson GJ. Frontline Gastroenterology 2019;10:292-299.

\begin{abstract}
Acute pancreatitis (AP) is characterised by inflammation of the exocrine pancreas and is associated with acinar cell injury and both a local and systemic inflammatory response. AP may range in severity from self-limiting, characterised by mild pancreatic oedema, to severe systemic inflammation with pancreatic necrosis, organ failure and death. Several international guidelines have been developed including those from the joint International Association of Pancreatology and American Pancreatic Association, American College of Gastroenterology and British Society of Gastroenterology. Here we discuss current diagnostic and management challenges and address the common dilemmas in AP.
\end{abstract}

\section{EPIDEMIOLOGY}

The UK incidence of acute pancreatitis (AP) is estimated as $15-42$ cases per 100000 per year and is rising by $2.7 \%$ each year. ${ }^{1}$ AP has a mortality rate of $1 \%-7 \%$ which increases to around 20\% in patients with pancreatic necrosis. ${ }^{2}$ The mortality rate is influenced by the severity of the disease with several prognostic factors having been described. The presence of persistent organ failure is associated with the highest mortality, which is as high as $60 \%$ in some series. ${ }^{3}$ Gallstone pancreatitis is more common in women over the age of 60, especially among those with microlithiasis, while alcoholic pancreatitis is more frequent in males. ${ }^{4}$

\section{AETIOLOGY}

Several aetiological factors have been described for AP although in up to $30 \%$ of cases an aetiological factor cannot be identified (termed idiopathic pancreatitis). ${ }^{5}$ The presence of microlithiasis accounts for $80 \%$ of idiopathic pancreatitis. ${ }^{6}$ In the UK, gallstones followed by alcohol intake are responsible for $75 \%$ of cases of $\mathrm{AP}^{5}$ The most common cause worldwide is alcohol consumption. Table 1 demonstrates other aetiologies.

\section{PATHOPHYSIOLOGY}

The initiating event in AP is due to acinar cell injury and impaired secretion of zymogen granules and involves extracellular neural and vascular mechanisms as well as intracellular mechanisms (such as intracellular enzyme activation, calcium accumulation and heat shock protein activation). ${ }^{78}$ Increased calcium transients potentiate co-localisation of zymogen and lysosome granules and ultimately premature conversion of typsinogen to trypsin. ${ }^{9}$ Medications that may cause AP through acinar cell injury include azathioprine, corticosteroids and thiazide diuretics. Ethanol-induced pancreatitis has different pathophysiological mechanisms. Ethanol is directly toxic to the acinar cell, leading to inflammation and membrane destruction. There is also evidence that ethanol increases pancreatic ductal pressure favouring retrograde flow and intra-pancreatic enzymatic activation. ${ }^{10}$ It is likely that the ischaemia-reperfusion injury plays a role in the development of AP, which is supported by the importance of early aggressive fluid resuscitation. ${ }^{11}$ Microvascular changes may lead to increased pancreatic vascular permeability, oedema, haemorrhage and pancreatic necrosis. These hypotheses have led to detection of novel molecular therapeutic targets such as tumour necrosis factor $-\alpha$ and interleukin- 6 , both important activators of the inflammatory response in $\mathrm{AP}^{12} \mathrm{~A}$ recent Cochrane review including 84 randomised controlled trials (RCTs) examined the efficacy of specific medical therapies in the treatment of AP; however, none of these showed clinical benefit or decreased shortterm mortality over standard supportive treatment with intravenous fluids, electrolytes and organ support. ${ }^{13}$ As such, there does not appear to be any current role for specific, targeted medical interventions in the management of AP. 
Table 1 Aetiology and pathogenesis of acute pancreatitis

\begin{tabular}{|c|c|}
\hline $\begin{array}{l}\text { Pathogenesis of acute } \\
\text { pancreatitis }\end{array}$ & Aetiology \\
\hline \multirow[t]{7}{*}{ Ductal obstruction } & Gallstones \\
\hline & Alcohol* $^{*}$ \\
\hline & $\begin{array}{l}\text { Post endoscopic retrograde } \\
\text { cholangiopancreatography }\end{array}$ \\
\hline & Malignancy \\
\hline & Mucinous tumours \\
\hline & Pancreas divisum \\
\hline & Sphincter of Oddi dysfunction \\
\hline \multirow[t]{5}{*}{ Acinar cell injury } & Alcohol* $^{*}$ \\
\hline & Trauma \\
\hline & Ischaemia \\
\hline & $\begin{array}{l}\text { Drugs (eg, corticosteroids, azathioprine } \\
\text { and thiazides) }\end{array}$ \\
\hline & Viruses \\
\hline \multirow{5}{*}{$\begin{array}{l}\text { Defective intracellular } \\
\text { transport }\end{array}$} & Alcohol* $^{*}$ \\
\hline & Hereditary \\
\hline & Hypercalcaemia \\
\hline & Hypertriglyceridaemia \\
\hline & Autoimmune \\
\hline
\end{tabular}

*Alcohol triggers acute pancreatitis via multiple mechanisms.

\section{DIAGNOSTIC APPROACH}

The diagnosis of AP must be considered in any patient presenting with abdominal pain. History and examination can be indicative of AP ; however, two out of the following three criteria should be met for diagnosis:

- Typical history.

- Elevated serum amylase or lipase (>3 ULN).

- Imaging (CT, MRI or ultrasound) consistent with acute pancreatitis.

\section{HISTORY}

A thorough history is required to determine the nature of the presenting abdominal pain, and for the presence of risk factors for pancreatic disease. Age and sex are important demographics because the two most common causes of AP differ. Gallstone pancreatitis is seen most commonly in patients with gallbladder disease, typically women over the age of 60 , while alcoholic pancreatitis is seen more frequently in men, and generally at a younger age than those with gallstone pancreatitis. ${ }^{1}$ Metabolic, drug-related and procedural aetiologies should be considered. A history of previous AP should be documented. A family history is important to exclude hereditary pancreatitis and familial cancer syndromes. All medication, and in particular new medicines, should be reviewed.

The most common presenting pattern of pain is severe epigastric pain that radiates to the back, is exacerbated by movement and is alleviated by leaning forwards. Patients may appear agitated, confused and in distress. They may give a history of anorexia, nausea, vomiting and reduced oral intake. ${ }^{14} \mathrm{~A}$ history of symptoms in keeping with associated cholangitis should be sought.

\section{PHYSICAL EXAMINATION}

Patients usually have signs of hypovolaemia and may appear diaphoretic, tachycardic and tachypnoeic. Fever may occur due to either cytokine release as part of the normal inflammatory response or may represent complicated pancreatitis, for example, pancreatic necrosis with or without infection. Reduced breath sounds and stony dull chest percussion suggest a pleural effusion, which may rarely be present on initial presentation although commonly develop as a later complication. ${ }^{15}$ The abdominal examination may reveal a tender and distended abdomen with voluntary guarding and with reduced bowel sounds if there is an associated ileus. Clinical signs of hypocalcaemia are rare but may be evident. Haemorrhagic pancreatitis is very rare and may cause ecchymoses of the periumbilical skin (Cullen's sign), within the flanks (Grey-Turner's sign) or over the inguinal ligament (Fox's sign). ${ }^{16}$ Other important differentials of retroperitoneal haemorrhage include ruptured abdominal aneurysm and ruptured ectopic pregnancy.

\section{LABORATORY INVESTIGATIONS}

Routine blood tests including liver enzymes, triglycerides and calcium should be obtained. Elevations in creatinine and urea suggest acute kidney injury secondary to third space fluid loss and intravascular depletion. Haemoconcentration is associated with an increased risk of developing pancreatic necrosis. In the absence of choledocholithiasis, liver function tests are usually relatively normal. An elevated alanine aminotransferase (ALT) at presentation suggests a likely biliary origin. A meta-analysis found that an elevated serum ALT concentration of $150 \mathrm{IU} / \mathrm{L}$ or more within 48 hours of symptom onset had a positive predictive value of $85 \%$ in predicting a gallstone aetiology in patients with $\mathrm{AP}^{17}$

Elevated levels of serum amylase or lipase ( $>3$ ULN) support, but are not pathognomic for a diagnosis of AP. Conversely, amylase and lipase may not reach the diagnostic threshold in cases of AP; it is therefore necessary to have a low threshold for treating patients when there is a high index of suspicion. The diagnostic performance of these tests decreases in the hours and days after the onset of AP, and so additional investigations should be performed if there is suspicion of established AP. Early and serial C reactive protein testing is used in AP as an indicator of severity and progression of inflammation. Arterial oxygenation should be closely monitored and hypoxia treated with supplemental oxygen. Arterial blood gas sampling should be considered in order to assess both oxygenation and acid-base status.

\section{IMAGING}

Radiographic studies are not used for diagnosis of AP, but may determine aetiology and exclude alternative 
diagnoses. A chest radiograph may show basal atelectasis and a pleural effusion. Abdominal radiograph may reveal a sentinel loop (isolated dilatation of a segment of gut) adjacent to the pancreas, demonstrate calcified gallstones (present in only 15\%-20\% of all cases with proven gallstones) $)^{18}$ or demonstrate pancreatic calcification as a feature of chronic pancreatitis.

Trans-abdominal ultrasound is the preferred initial study in suspected gallstone pancreatitis as it is inexpensive, available at the bedside and allows examination of the gallbladder and biliary tree. The sensitivity of conventional ultrasound in detecting AP is up to $75 \%$ but is limited by overlying bowel gas in 25\%-30\% of patients. ${ }^{19}$ Patients that become systemically unwell, septic or who do not improve should have a multiphase contrast-enhanced CT scan to rule out peripancreatic collections, necrosis, abscesses and vascular complications of pancreatitis (eg, development of portal venous thrombus, pseudoaneurysms or haemorrhage). Areas of reduced pancreatic parenchymal enhancement indicate pancreatic necrosis. While CT is the preferred initial modality for staging AP and detecting vascular complications, it is not advised within the first 48 hours of admission (unless there is diagnostic uncertainly) as this has been associated with increased length of stay, underestimation of the degree of pancreatic necrosis and with no improvement in patient outcomes. ${ }^{20}$ For serial examinations, MRI is gaining favour with the use of MR cholangiopancreatography (MRCP) sequences to detect/exclude aetiological factors (including biliary and pancreatic stones), improved depiction of the solid and liquid components of pancreatic and peripancreatic collections (thereby facilitating planning of drainage procedures), and better characterisation of pancreatic parenchyma including acute inflammation, residual volume and fibrotic change (from previous insults). ${ }^{21-23}$ Endoscopic retrograde cholangiopancreatography (ERCP) is only recommended acutely in cases of gallstone pancreatitis complicated by cholangitis. A meta-analysis found no evidence that early routine ERCP significantly affects mortality or morbidity in biliary pancreatitis other than in those patients with coexisting cholangitis or biliary obstruction. ${ }^{24}$ In patients considered to have idiopathic AP, after negative work-up for biliary aetiology, endoscopic ultrasound (EUS) should be considered to detect microlithiasis and cross-sectional imaging should be reviewed to exclude pancreatic neoplasm, particularly relevant in patients aged $>50$ years. A systematic review including 416 patients with idiopathic AP reported a 32\%-88\% diagnostic yield of EUS, detecting either biliary sludge or signs of chronic pancreatitis. ${ }^{25}$ If an EUS is normal, secretin stimulated MRCP may be considered to assess for rare anatomical abnormalities. ${ }^{26}$

\section{PROGNOSTICATION IN AP}

Several prognostic scores have been developed or adapted to predict disease severity. According to the
International Association of Pancreatology and American Pancreatic Association (IAP/APA) guidelines, the presence of a systemic inflammatory response syndrome (SIRS) at admission and persistent SIRS at 48 hours both predict severe $\mathrm{AP}^{26}$ Persistent SIRS was associated with a mortality of $25 \%$ compared with $8 \%$ for transient SIRS. ${ }^{27}$ The sensitivity of persistent SIRS for predicting mortality is $77 \%-89 \%$ and specificity $79 \%-86 \% \%^{27-29}$ and of SIRS at admission $100 \%$ and $31 \%$, respectively. ${ }^{28}$ Other scoring systems do existsuch as APACHEII, Ranson and modified Glasgow score-but none of these are superior or inferior to (persistent) SIRS at predicting mortality. ${ }^{30}$

\section{TREATMENT}

The main goal of initial treatment is to alleviate symptoms and prevent complications by reducing pancreatic secretory stimuli and correction of fluid and electrolyte abnormalities. Initially, patients should be fluid resuscitated and kept nil by mouth with bowel rest when nausea, vomiting or abdominal pain are present. Supportive care continues until pain is resolved and diet restarted. The majority of patients will improve within 3-7 days of conservative management. Patients with organ failure or poor prognostic signs (persistent SIRS, Glasgow score $>3$, APACHE score $>8$ and Ranson score $>3$ ) should be assessed for admission to a high dependency unit. ${ }^{26}$

\section{INITIAL RESUSCITATION}

Resuscitation with intravenous fluids, analgesics and antiemetics should form part of the initial treatment even before the diagnosis of AP is made. Goal-directed rehydration with Ringer's lactate solution (or Hartmann's) is recommended ${ }^{31}$ at a rate of $5-10 \mathrm{~mL} / \mathrm{kg} /$ hour until resuscitation goals are reached. ${ }^{26} \mathrm{~A}$ recent triple-blind RCT compared Ringer's lactate to normal saline in AP and found that Ringer's lactate was associated with an anti-inflammatory effect which was attributed to the properties of lactate. ${ }^{32} \mathrm{~A}$ urinary catheter should be inserted in severe AP in order to record accurate fluid balance. Overly aggressive hydration leads to increased rates of sepsis, the need for more mechanical ventilation and higher mortality ${ }^{33}{ }^{34}$; therefore, infusion rates should be carefully tailored to individual patients, taking into account factors such as age and comorbidities. Adequate early fluid resuscitation is the single most important aspect of the medical management, reducing organ failure and in-hospital mortality. ${ }^{35}$ Effective pain control is important in order to prevent diaphragmatic splinting, thereby reducing the risk of respiratory complications. The most commonly used drugs are opiates (morphine or fentanyl) either for breakthrough pain or as patient-controlled analgesia. Close monitoring of arterial oxygenation, acid-base balance and blood glucose should follow the intensive treatment modes of other critically ill patients. 


\section{SEVERE PANCREATITIS}

The treatment of severe pancreatitis should be delivered in a high dependency unit. Insulin should be administered to maintain strict glucose control as this has been associated with reductions in morbidity and mortality in critical illness. ${ }^{36}$ Hypocalcaemia and hypomagnesaemia should be identified and treated to avoid the development of cardiac arrhythmias.

\section{ANTIBIOTICS IN AP}

The use of antibiotics in non-infected pancreatitis is not currently recommended as there is no clear evidence of benefit. Prophylactic antibiotics have not been shown to reduce mortality, extra-pancreatic infections or the need for surgical intervention. A meta-analysis demonstrated no difference in the rates of infected necrosis, surgery or mortality between patients receiving antibiotics and those receiving a placebo for the treatment of severe $\mathrm{AP}^{37}$ Some studies have shown a small benefit in cases of severe necrotising pancreatitis; therefore, antibiotic use should be restricted to patients in whom infection is strongly suspected. ${ }^{38}$ It is possible that injudicious use of antibiotics in walled off necrosis (WON) may lead to the development of resistant organisms once infection does develop.

\section{COLLECTIONS IN SEVERE PANCREATITIS}

The management of pancreatic and peripancreatic collections has evolved over the past decade. The 2012 revised Atlanta criteria discern four types of peripancreatic fluid collections in AP depending on the content, degree of encapsulation and time (figure 1).
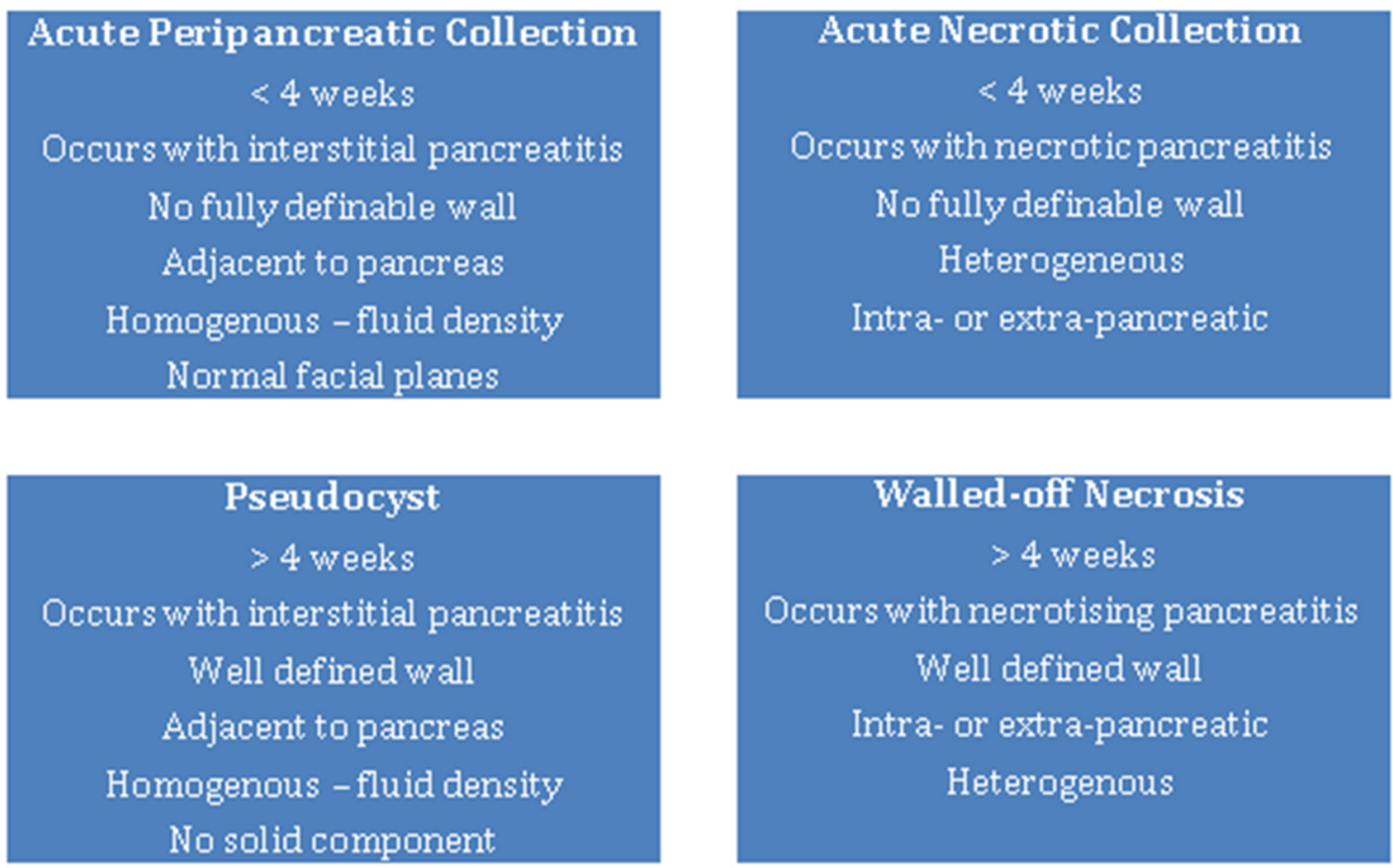

Indications to drain pancreatic collections include infection and symptomatic sterile necrosis, while persistent collections that are asymptomatic may be observed. WON typically occurs $>4$ weeks after the onset of $\mathrm{AP}^{39}$ Infected pancreatic necrosis should be diagnosed based on clinical signs and the presence of gas on imaging, fine needle aspiration is not routinely required. ${ }^{26}$ The choice and progression of intervention depends on individual patient factors including the anatomy of the collection and may involve an endoscopic or radiological approach. Open (surgical) necrosectomy is no longer recommended in necrotising pancreatitis following the landmark PANTER trial (Minimally Invasive Step Up Approach versus Maximal Necrosectomy in Patients with Acute Necrotising Pancreatitis) published in 2010 which showed that a minimally invasive step-up approach compared with open necrosectomy reduced the rate of major complication and death among patients with necrotising pancreatitis and infected necrotic tissue. ${ }^{40}$ In general, many patients are suitable for a 'step-up' approach, starting with conservative management and then to either percutaneous drainage or endoscopic transluminal drainage in selected patients within experienced high-volume endoscopic centres. Patients who do not respond to initial percutaneous or endoscopic drainage may require either upsizing to larger or more numerous percutaneous drains or endoscopic necrosectomy in those with an endoscopically placed lumen apposing metal stent (LAMS). A recent meta-analysis has indicated that patients with WON drained endoscopically with LAMS may do better than those

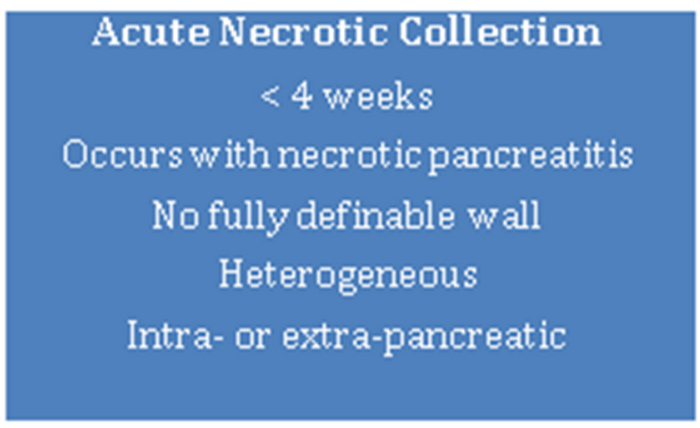

Figure 1 Atlanta classification of pancreatic fluid collections. ${ }^{39}$ 
drained with plastic stents. ${ }^{41}$ A large UK case series has demonstrated safety of LAMS in WON, in contrast to a series in the USA that showed a significant complication rate from LAMS. ${ }^{42}{ }^{43}$ (In our practice, we favour endoscopic drainage with large diameter LAMS in cases of WON when anatomically favourable, and often insert a pigtail plastic stent through the LAMS to prevent solid debris blocking the LAMS and precipitating a septic episode. We image the patient at 4 weeks and remove the LAMS at that point. If the collection persists, we would consider retaining the patency of the tract with plastic pigtail stents.)

Pseudocysts may resolve spontaneously; however, do require drainage in the case of complications (infection, biliary or duodenal obstruction) or if the patient is symptomatic with pain. Endoscopic cystgastrostomy with multiple plastic pigtail stents is the preferred drainage option although percutaneous drainage may be considered in unfavourable anatomy. The use of LAMS for the drainage of pseudocysts is well described for ease, but the risks, clinical benefit and cost implications have not yet been studied. The timing and choice of approach requires multidisciplinary collaboration. Figure 2 demonstrates CT findings in AP, and figure 3 demonstrates the endoscopic view of a LAMS alongside an endoscopic necrosectomy.

\section{NUTRITION}

In cases of mild pancreatitis, enteral nutrition should be recommenced as soon as abdominal pain has

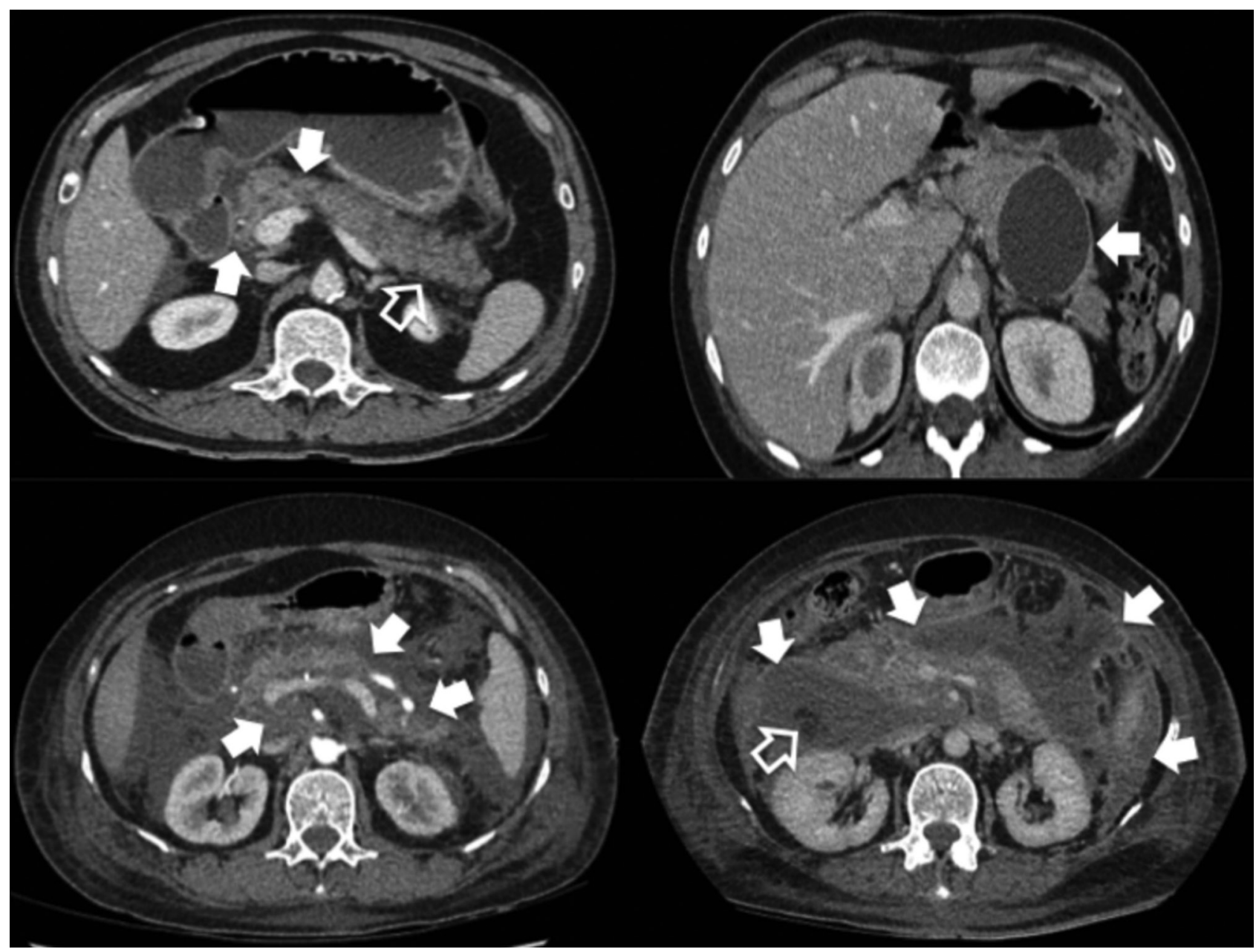

Figure 2 CT findings in acute pancreatitis. Top left: acute interstitial pancreatitis; post-contrast portal venous phase axial CT image through the pancreas. The pancreas enhances homogeneously but there is ill-defined peripancreatic fat stranding centred on the head and body of the pancreas (white solid arrows) extending to involve the tail (white clear arrow). Note a small volume of free fluid in the lesser sac (interposed between the head of the pancreas and gastric antrum) and in the hepatorenal space. Top right: pancreatic pseudocyst; post-contrast portal venous phase axial CT image through the pancreatic tail. At this stage, acute inflammation has settled but there is a well-defined fluid density cystic lesion in the tail of pancreas (white solid arrow), with normally enhancing pancreatic tissue on either side of the lesion. Bottom left: acute necrotic collection; postcontrast late arterial phase axial CT image through the pancreas. Note patchy areas of pancreatic parenchymal hypoenhancement in the posterior head and tail of pancreas (white solid arrows). There is ill-defined peripancreatic fat stranding with free fluid crossing between retroperitoneal and peritoneal compartments, involving intra-pancreatic and extra- pancreatic tissues. Bottom right: early walled off necrosis ; post-contrast portal venous phase axial CT imaging through the pancreas. At this stage, ill-defined peripancreatic collections that cross between anatomical compartments are seen to become more organised with thick enhancing walls (solid white arrows) and heterogeneous internal debris (eg, fat density components, white clear arrow). 


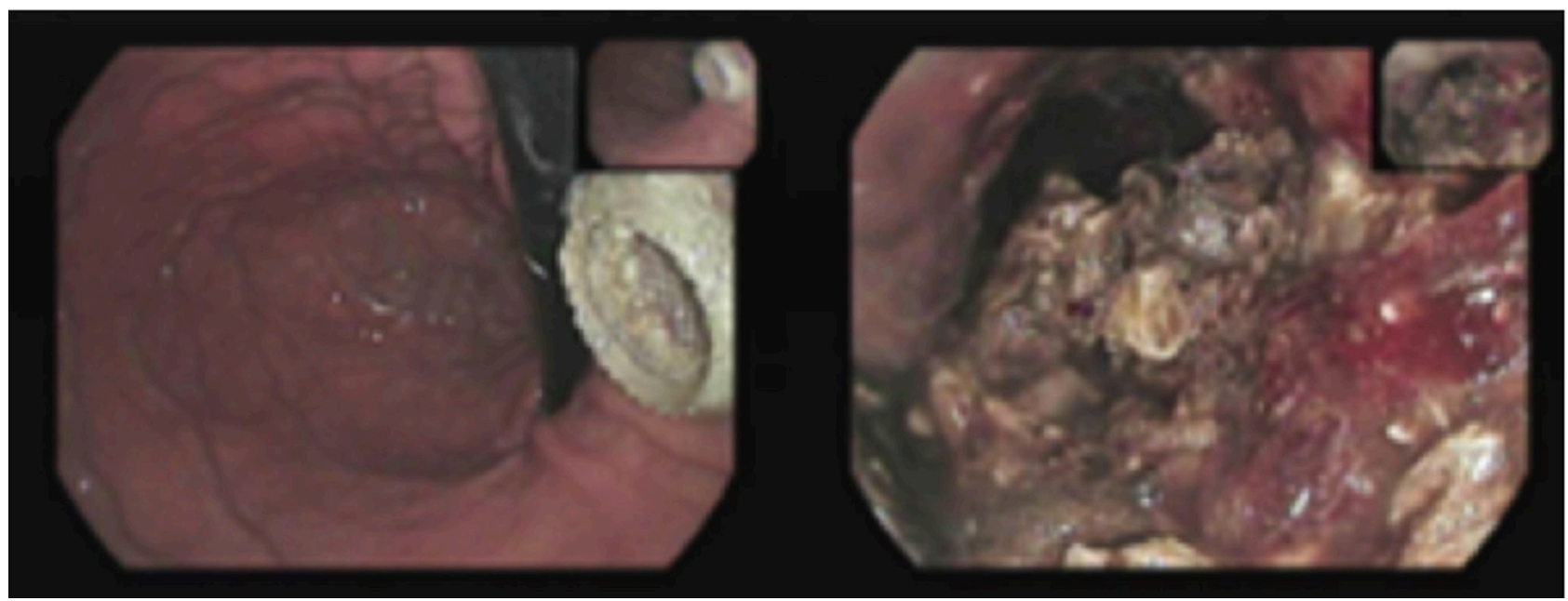

Figure 3 Endoscopic image of lumen apposing metal stent (left) and endoscopic necrosectomy (right).

subsided. ${ }^{44}$ In severe pancreatitis, patients should be kept nil by mouth until fully resuscitated, usually after 48 hours, at which point normal enteral diet (if tolerated) or enteral tube feeding should be commenced. ${ }^{26}$ Two meta-analyses have demonstrated that enteral nutrition, compared with parenteral nutrition, decreases sepsis, organ failure, the need for surgical intervention and mortality. ${ }^{45} 46$ Post-pancreatic feeding is no longer recommended unless there is mechanical gastric outlet obstruction or the patient is unable to tolerate nasogastric tube feeding. ${ }^{47}$ Parenteral nutrition should be reserved for patients who are unable to reach nutritional goals with nasojejunal feeding. A delay of up to 5 days in the initiation of parenteral nutrition may be appropriate to allow for restarting of oral or enteral feeding. ${ }^{26}$ Pancreatic enzyme supplementation should be prescribed to patients with symptoms of pancreatic exocrine insufficiency. ${ }^{48}$

\section{ALCOHOL-INDUCED PANCREATITIS}

Patients with alcohol-induced pancreatitis may need alcohol-withdrawal prophylaxis. Benzodiazepines, thiamine, folic acid and multivitamins are generally used. Dedicated outpatient follow-up visits are advised to prevent recurrence. ${ }^{49}$

\section{GALLSTONE PANCREATITIS}

All patients presenting with gallstone pancreatitis should be considered for cholecystectomy when they are well enough to undergo surgery. In cases of mild biliary pancreatitis, cholecystectomy should ideally be performed during the index admission or within 2 weeks of discharge as interval cholecystectomy is associated with a significant risk of readmission for recurrent biliary events. ${ }^{26}$ A systematic review found an $18 \%$ readmission rate for recurrent biliary events a medium of 6 weeks after index admission for mild gallstone pancreatitis. ${ }^{50}$ In cases of severe gallstone pancreatitis, cholecystectomy may need to be delayed until collections have improved, unless the patient is well enough for surgery and the gallbladder is some distance from the collection. ${ }^{26}$ In surgically unfit or frail elderly patients, ERCP with biliary sphincterotomy may be considered as definitive treatment although the risks of sphincterotomy should be balanced against the risk of recurrent biliary events. ${ }^{51}$

\section{PROGNOSIS}

Most patients with AP will improve within 1 week of conservative management and be well enough for discharge. The aetiology should be identified, and a plan to prevent recurrence should be initiated before hospital discharge. Long-term prognosis is based on the aetiological factor and patient compliance to lifestyle modifications. AP generally resolves and leaves pancreatic function intact. Many patients progress to recurrent AP or chronic pancreatitis, and the risk is higher among smokers, alcoholics and men.

\section{NCEPOD REPORT (2016)}

In 2016 the National Confidential Enquiry into Patient Outcomes and Death (NCEPOD) published a report into the care of patients with AP within the National Health Service. Overall $45 \%$ of patients received 'good practice', room for improvement was identified in 52\% and $3 \%$ of patients had 'less than satisfactory care'. Key areas for improvement were better documentation of physiological parameters and early warning scores, increased multidisciplinary input to manage comorbidities, accurate assessment of nutritional risk, simplified rapid referral pathways for ERCP and timely cholecystectomy in patients with biliary pancreatitis. In addition, it concluded that all patients with severe AP requiring radiological, endoscopic or surgical intervention should be managed within a specialist tertiary referral centre. The report found an overall mortality of 13\% in AP and recommended that all deaths are discussed in morbidity and mortality meetings with learning shared through network meetings. ${ }^{52}$ 
Contributors All authors contributed equally to this review.

Funding The authors have not declared a specific grant for this research from any funding agency in the public, commercial or not-for-profit sectors.

Competing interests None declared.

Patient consent Not required.

Provenance and peer review Not commissioned; externally peer reviewed.

Data sharing statement There are no unpublished data in this article.

\section{REFERENCES}

1 Roberts SE, Akbari A, Thorne K, et al. The incidence of acute pancreatitis: impact of social deprivation, alcohol consumption, seasonal and demographic factors. Aliment Pharmacol Ther 2013;38:539-48.

2 McLean R, Jones M, Kanakala V, et al. PWE-204 Acute pancreatitis: incidence, management and outcome trends over 15 years. Gut 2015;64:A301-2.

3 Rasslan R, Novo F, Bitran A, et al. Management of infected pancreatic necrosis: state of the art. Rev Col Bras Cir 2017;44:521-9.

4 Roberts SE, Morrison-Rees S, John A, et al. The incidence and aetiology of acute pancreatitis across Europe. Pancreatology 2017;17:155-65.

5 Toh SK, Phillips S, Johnson CD. A prospective audit against national standards of the presentation and management of acute pancreatitis in the South of England. Gut 2000;46:23943.

6 Lee JK, Enns R. Review of idiopathic pancreatitis. World J Gastroenterol 2007;13:6296.

7 Binker MG, Cosen-Binker LI. Acute pancreatitis: the stress factor. World J Gastroenterol 2014;20:5801.

8 Frossard J-L, Steer ML, Pastor CM. Acute pancreatitis. The Lancet 2008;371:143-52.

9 van Acker GJ, Perides G, Steer ML. Co-localization hypothesis: a mechanism for the intrapancreatic activation of digestive enzymes during the early phases of acute pancreatitis. World $J$ Gastroenterol 2006;12:1985-90.

10 Clemens DL. Alcoholic pancreatitis: new insights into the pathogenesis and treatment. World J Gastrointest Pathophysiol 2016;7:48.

11 Yang R, Tenhunen J, Tonnessen TI. HMGB1 and Histones play a significant role in inducing systemic inflammation and multiple organ dysfunctions in severe acute pancreatitis. Int J Inflam 2017;2017:1-6.

12 Staubli SM, Oertli D, Nebiker CA. Laboratory markers predicting severity of acute pancreatitis. Crit Rev Clin Lab Sci 2015;52:273-83.

13 Moggia E, Koti R, Belgaumkar AP, et al. Pharmacological interventions for acute pancreatitis. Cochrane Upper GI and Pancreatic Diseases Group, editor. Cochrane Database Syst Rev 2017.

14 Banks PA, Freeman ML. Practice parameters committee of the American College of Gastroenterology. Practice guidelines in acute pancreatitis. Am J Gastroenterol 2006;101:2379-400.

15 Browne GW. Pathophysiology of pulmonary complications of acute pancreatitis. World J Gastroenterol 2006;12:7087.

16 Mookadam F, Cikes M. Images in clinical medicine. Cullen's and Turner's signs. N Engl J Med 2005;353:1386.

17 Tenner S, Dubner H, Steinberg W. Predicting gallstone pancreatitis with laboratory parameters: a meta-analysis. Am J Gastroenterol 1994;89:1863-6.

18 Bortoff GA, Chen MYM, Ott DJ, et al. Gallbladder stones: imaging and intervention. Radiographics 2000;20:751-66.

19 Manfredi R, Brizi MG, Canadè A, et al. Imaging of acute pancreatitis. Rays 2001;26:135-42.
20 Spanier BWM, Nio Y, van der Hulst RWM, et al. Practice and yield of early CT Scan in acute pancreatitis: a dutch observational multicenter study. Pancreatology 2010;10(23):222-8.

21 Tirkes T, Lin C, Fogel EL, et al. Sandrasegaran K. $T_{1}$ mapping for diagnosis of mild chronic pancreatitis: $T_{1}$ Mapping of chronic pancreatitis. J Magn Reson Imaging 2017;45:1171-6.

22 Morgan DE, Baron TH, Smith JK, et al. Pancreatic fluid collections prior to intervention: evaluation with MR imaging compared with CT and US. Radiology 1997;203:773-8.

23 Correction. American Journal of Roentgenology 2010;195:S42.

24 Tse F, Yuan Y. Early routine endoscopic retrograde cholangiopancreatography strategy versus early conservative management strategy in acute gallstone pancreatitis. In: Cochrane database of systematic reviews. Chichester, UK: John Wiley \& Sons, Ltd, 2012.

25 Wilcox CM, Varadarajulu S, Eloubeidi M. Role of endoscopic evaluation in idiopathic pancreatitis: a systematic review. Gastrointest Endosc 2006;63:1037-45.

26 Working Group IAP/APA Acute Pancreatitis Guidelines. IAP/ APA evidence-based guidelines for the management of acute pancreatitis. Pancreatology 2013;13:e1-15.

27 Mofidi R, Duff MD, Wigmore SJ, et al. Association between early systemic inflammatory response, severity of multiorgan dysfunction and death in acute pancreatitis. Br J Surg 2006;93:738-44.

28 Buter A, Imrie CW, Carter CR, et al. Dynamic nature of early organ dysfunction determines outcome in acute pancreatitis. $\mathrm{Br}$ J Surg 2002;89:298-302.

29 Singh VK, Wu BU, Bollen TL, et al. Early systemic inflammatory response syndrome is associated with severe acute pancreatitis. Clin Gastroenterol Hepatol 2009;7:124751.

30 Papachristou GI, Muddana V, Yadav D, et al. Comparison of BISAP, Ranson's, APACHE-II, and CTSI scores in predicting organ failure, complications, and mortality in acute pancreatitis. Am J Gastroenterol 2010;105:435-41.

31 Wu BU, Hwang JQ, Gardner TH, et al. Lactated Ringer's solution reduces systemic inflammation compared with saline in patients with acute pancreatitis. Clin Gastroenterol Hepatol 2011;9:710-7.

32 de-Madaria E, Herrera-Marante I, González-Camacho V, et al. Fluid resuscitation with lactated Ringer's solution vs normal saline in acute pancreatitis: A triple-blind, randomized, controlled trial. United European Gastroenterol J 2018;6:6372.

33 Mao EQ, Tang YQ, Fei J, et al. Fluid therapy for severe acute pancreatitis in acute response stage. Chin Med J 2009;122:169-73.

34 Mao EQ, Fei J, Peng YB, et al. Rapid hemodilution is associated with increased sepsis and mortality among patients with severe acute pancreatitis. Chin Med J 2010;123:163944.

35 Gardner TB, Vege SS, Pearson RK, et al. Fluid resuscitation in acute pancreatitis. Clin Gastroenterol Hepatol 2008;6:1070-6.

36 Mesotten D, Preiser JC, Kosiborod M. Glucose management in critically ill adults and children. Lancet Diabetes Endocrinol 2015;3:723-33.

37 Wittau M, Mayer B, Scheele J, et al. Systematic review and meta-analysis of antibiotic prophylaxis in severe acute pancreatitis. Scand J Gastroenterol 2011;46:261-70.

38 Piaścik M, Rydzewska G, Milewski J, et al. The results of severe acute pancreatitis treatment with continuous regional arterial infusion of protease inhibitor and antibiotic: a randomized controlled study. Pancreas 2010;39:863-7.

39 Banks PA, Bollen TL, Dervenis C, et al. Classification of acute pancreatitis--2012: revision of the Atlanta classification and definitions by international consensus. Gut 2013;62:102-11. 
40 van Santvoort HC, Besselink MG, Bakker OJ, et al. A step-up approach or open necrosectomy for necrotizing pancreatitis. $N$ Engl J Med Overseas Ed 2010;362:1491-502.

41 Bazerbachi F, Sawas T, Vargas EJ, et al. Metal stents versus plastic stents for the management of pancreatic walled-off necrosis: a systematic review and meta-analysis. Gastrointest Endosc 2018;87:30-42.

42 Venkatachalapathy SV, Bekkali N, Pereira S, et al. Multicenter experience from the UK and Ireland of use of lumen-apposing metal stent for transluminal drainage of pancreatic fluid collections. Endosc Int Open 2018;6:E259-65.

43 Bang JY, Navaneethan U, Hasan MK, et al. Non-superiority of lumen-apposing metal stents over plastic stents for drainage of walled-off necrosis in a randomised trial. Gut 2018.

44 Eckerwall GE, Tingstedt BB, Bergenzaun PE, et al. Immediate oral feeding in patients with mild acute pancreatitis is safe and may accelerate recovery--a randomized clinical study. Clin Nutr 2007;26:758-63.

45 Al-Omran M, AlBalawi ZH, Tashkandi MF, et al. Enteral versus parenteral nutrition for acute pancreatitis. In: Cochrane database of systematic reviews: Chichester, UK John Wiley \& Sons, Ltd, 2010.

46 Petrov MS, van Santvoort HC, Besselink MG, et al. Enteral nutrition and the risk of mortality and infectious complications in patients with severe acute pancreatitis: a meta-analysis of randomized trials. Arch Surg 2008;143:1111.

47 Eatock FC, Chong P, Menezes N, et al. A randomized study of early nasogastric versus nasojejunal feeding in severe acute pancreatitis. Am J Gastroenterol 2005;100:432-9.

48 Hollemans RA, Hallensleben NDL, Mager DJ, et al. Pancreatic exocrine insufficiency following acute pancreatitis: Systematic review and study level meta-analysis. Pancreatology 2018;18:253-62.

49 Nordback I, Pelli H, Lappalainen-Lehto R, et al. The recurrence of acute alcohol-associated pancreatitis can be reduced: a randomized controlled trial. Gastroenterology 2009;136:848-55.

50 van Baal MC, Besselink MG, Bakker OJ, et al. Timing of cholecystectomy after mild biliary pancreatitis: a systematic review. Ann Surg 2012;255:860-6.

51 McAlister V, Davenport E, Renouf E. The Cochrane Collaboration. Cholecystectomy deferral in patients with endoscopic sphincterotomy. In: Cochrane database of systematic reviews. Chichester, UK: John Wiley \& Sons, Ltd, 2007.

52 O'Reilly DA, McPherson SJ, Sinclair MT, et al. 'Treat the Cause': the NCEPOD report on acute pancreatitis. Br J Hosp Med 2017;78:6-7. 